\title{
¿INHABILIDAD SIN PÉRDIDA DE INVESTIDURA? ANÁLISIS DE LA ANTINOMIA ENTRE LA INHABILIDAD POR CAUSAR DAÑOS ANTIJURÍDICOS QUE INDEMNIZA EL ESTADO Y LA SANCIÓN DE LA PÉRDIDA DE LA INVESTIDURA: RESOLUCIÓN DESDE NORBERTO BOBBIO*
}

\author{
Héctor Fernando Olaya Vera** \\ Recibido: Octubre 4 de 2015 \\ Aprobado: Noviembre 24 de 2015
}

\section{RESUMEN}

En el 2008 en concepto dirigido al Ministerio del Interior, el Consejo de Estado insinuó la improcedencia de la pérdida de la investidura de congresista con fundamento en la inhabilidad del inciso final del artículo 122 constitucional, dejando entrever una incompatibilidad entre la aplicación del art.183 C.N numeral $1^{\circ}$ y la del art. 122 C.N inciso final, evento inédito en la jurisprudencia de esa corporación. En este texto, con fundamento en Norberto Bobbio, se sostiene que es jurídicamente procedente la pérdida de la investidura de congresista con fundamento en la inhabilidad del inciso final del artículo 122 constitucional, cuando estando vigente la condena, el pago se realiza luego de la inscripción de la candidatura.

Palabras claves: Pérdida de la investidura, Positivismo jurídico, Inhabilidad superable, Antinomia, Congresista.

INABILITY WITHOUT LOSING THE INVESTITURE? AN ANALYSIS FROM THE ANTINOMY BETWEEN WRONGFUL DAMAGE INABILITY INDEMNIFIED BY THE STATE AND THE SANCTION DUE TO THE LOSS OF THE INVESTITURE. AN ANSWER ACCORDING TO NORBERTO BOBBIO'S APPROACH

* El presente texto es un avance de la investigación "Antinomias entre el régimen constitucional de inhabilidades incompatibilidades y la acción de pérdida de la investidura”.

** Estudiante de Derecho de la Universidad Autónoma de Bucaramanga, integrante del Semillero de Investigación en Hermenéutica Jurídica -HERMES-adscrito al Centro de Investigaciones Socio-Jurídicas. hermes@unab.edu.co 


\section{ABSTRAC}

In 2008 in a resolution addressed to the Ministry of Interior, the State Council implied the inadmissibility of the investiture loss of Congressmen based on the inability of the final paragraph of Article 122 of the Constitution, suggesting an incompatibility between the application of art.183 CN numeral 1 and art. CN 122 last paragraph, an unprecedented event in the jurisprudence of that corporation. In this paper, based on Norberto Bobbio's approach, it is defended that is set to the law the investiture loss of Congressman based on the inability on the final paragraph of Article 122 of the Constitution, when the condemnation is in force, the payment is made after the enrollment of application..

Key Words: Investiture loss, Legal positivism, Beatable inability, Antimony, Congressmen.

INCAPACIDADE SEM PERDA DE INVESTIDURA? ANÁLISE DA CONTRADIÇÃO ENTRE A INABILIDADE POR CAUSAR DANOS ANTIJURÍDICOS QUE INDENIZAM O ESTADO E A PUNIÇÃO DA PERDA DA INVESTIDURA: SEGUNDO A RESOLUÇÃO DE NORBERTO BOBBIO

\section{RESUMO}

Em 2008, num conceito dirigido ao Ministério do Interior, o Conselho de Estado insinuou a inadmissibilidade da destituição do cargo de deputado federal com base na incapacidade do último parágrafo do artigo $122 .{ }^{\circ} \mathrm{da}$ Constituição, o que sugere uma incompatibilidade entre a aplicação do art.183 CN numeral 1 e do art. $122 \mathrm{CN}$ do inciso final, evento sem precedentes na jurisprudência dessa corporação. Neste trabalho, baseado em Norberto Bobbio, argumenta-se que é legalmente procedente a perda de mandato de deputado federal em razão da deficiência no último parágrafo do artigo $122 .^{\circ}$ da Constituição, quando a condenação ainda é válida, o pagamento é feito logo após a inscrição do candidato.

Palavras-chave: Destituição do cargo, O positivismo jurídico, Deficiência superável, Antinomia, Congressista. 


\section{INTRODUCCIÓN}

El tema objeto de análisis del presente texto lo planteó la Sala de Consulta y Servicio Civil del Consejo de Estado ${ }^{1}$ : no cabe la pérdida de la investidura de congresista con fundamento en la inhabilidad inciso final del artículo 122 constitucional, que establece la prohibición para ser inscrito o elegido a cargos de elección popular y contratar con el Estado, a quien por un actuar doloso o gravemente culposo ocasionase un daño antijurídico que el Estado haya tenido que indemnizar, cuando se deja de tener la condición de congresista.

Este pronunciamiento plantea un interrogante más amplio que en este escrito se pretende responder a la pregunta: ¿puede en todo evento sancionarse con la pérdida de la investidura de congresista a quien llega a tal dignidad transgrediendo la prohibición del inciso final del artículo 122 constitucional?

La cuestión no es baladí: los efectos sancionatorios de la pérdida de la investidura se extienden durante toda la vida del sancionado, impiden a perpetuidad ejercer cargos de elección popular; por su parte la inhabilidad referida prevé una excepción, lo que habilitaría el ejercicio del sufragio pasivo, consistente en el pago del monto económico asumido por el Estado en la indemnización.

Se está, tal parece, ante una antinomia. La aplicación de una y otra norma niega la aplicación de la contraria: imponer la perdida de la investidura a quien fue electo congresista pese ocasionar un daño, con dolo o culpa grave, que tuvo que ser indemnizado por el Estado, impide que luego de pagar el valor de la condena este pueda ser elegido a un cargo público; por el contrario habilitar esta última posibilidad exige hacer nugatoria la pérdida de la investidura como sanción político-disciplinaria que es.

Resolver esta posible contradicción de dos reglas jurídicas es uno de los propósitos de la investigación "Las antinomias entre los regímenes constitucionales de inhabilidades e incompatibilidades de los congresistas y el de la pérdida de la investidura", adelantada dentro del Semillero de Investigación en Hermenéutica Jurídica -HERMESadscrito al grupo de investigación en Hermenéutica Jurídica del Centro de Investigaciones Socio-Jurídicas "Laureano Gómez Serrano" de la Universidad Autónoma de Bucaramanga.

1 Consejo de Estado. Sala de Consulta y Servicio Civil. C.P. William Zambrano Cetina. Concepto del 03 de julio de 2008. Rad.: 11001-03-06-000-2008-00029-00(1894). Consultante: Ministerio del Interior 
Para resolver el debate planteado, se acogerá como fundamento teórico, las disquisiciones del notable positivista italiano Norberto Bobbio.

Este texto es de interés en cuanto a que el evento atrás señalado es inédito en la jurisprudencia del Consejo de Estado. Por tal virtud, al abordar este caso hipotético se constituye en un esfuerzo dogmático para establecer si se pueden afectar los derechos políticos mediante la pérdida de investidura de quien incurre en la inhabilidad del inciso final del artículo 122 superior, o si por el contrario su hipótesis debe ser excluida como causal de la sanción de la pérdida de la investidura de congresista.

Se busca argumentar a favor de la procedencia de la pérdida de la investidura por la inhabilidad constitucional del inciso final del art. 122 C.N., por constituir esta una inhabilidad para acceder al cargo de congresista, y no ser superable jurídicamente en modo alguno su transgresión para llegar a dicho cargo de elección popular.

Para cumplir los propósitos de este escrito, se dividirá en cinco partes. En la primera se abordará el concepto y los tipos de antinomias normativas, luego las diferentes maneras en las que estas se pueden desatar. Enseguida se caracterizará más en lo fáctico y en lo jurídica la antinomia que nos interesa en este texto, y después se postularán las soluciones posibles para la misma. Finalmente, se expondrán las conclusiones.

\section{EL PROBLEMA DE LAS ANTINOMIAS NORMATIVAS DESDE LA TEORÍA DEL ORDENAMIENTO JURÍDICO DE NORBERTO BOBBIO}

En su acercamiento al Derecho desde un enfoque normativo, el teórico italiano Norberto Bobbio con posterioridad a la explicación de su Teoría de la Noma Jurídica y en el desarrollo de la construcción de su Teoría del Ordenamiento Jurídico advierte que los ordenamientos jurídicos tienen una marcada tendencia a constituirse en sistemas. Este fenómeno resulta particularmente importante de abordar en la construcción de una Teoría General del Derecho, en tanto que para Bobbio a pesar de que recurrentemente juristas y filósofos jurídicos se refieren al Derecho en abstracto como un sistema, teóricamente el concepto de sistema normativo no ha sido estudiado a profundidad, a excepción del estudio y clasificación del mismo realizado por Kelsen (2011), quien identifica a un sistema jurídico cuando "puede exigir una determinada conducta justamente en cuanto enlaza al comportamiento opuesto un perjuicio" (p.39). 
Con el objetivo de formular una significación específica al concepto de sistema normativo acorde a sus posturas teóricas frente al Derecho y la experiencia jurídica, Bobbio inicia su disertación al colocar de presente que aislado del ámbito estrictamente jurídico, un sistema es entendido como una totalidad ordenada, o sea, un conjunto de entes entre los cuales existe cierto orden que requiere para su constitución, no solo que los entes que componen al sistema estén en relación con el todo, sino que así mismo exige que dichos entes se encuentren en relación de coherencia entre sí. (Bobbio, 1997, p.177).

A partir de dicha definición de sistema, Bobbio se cuestiona sobre en qué medida un ordenamiento jurídico realmente puede llegar a constituirse en un sistema normativo y qué requisitos debería cumplir el ordenamiento para lograrlo.

Para llegar a determinar la significación específica que pretende del concepto de sistema normativo, en el desarrollo de su teoría Bobbio expone que derivado del uso que a lo largo de la evolución del pensamiento iusfilosófico y la jurisprudencia se le ha dado al concepto de sistema normativo, es posible reconocerle fundamentalmente a estas tres significaciones.

La primera significación, dice Bobbio, asocia el concepto de sistema normativo con el de sistema deductivo, entendiéndose a partir de ella que un ordenamiento es un sistema en cuanto todas las normas jurídicas del ordenamiento se derivan de algunos principios generales considerados del mismo modo que los postulados de un sistema científico (Bobbio, 1997)

Por su parte, la segunda significación, surge en el marco de la ciencia moderna del Derecho derivada de la pandectística alemana y del paso de la jurisprudencia exegética a la jurisprudencia sistemática. Usa el concepto de sistema para indicar un ordenamiento de la materia dado a través de un procedimiento inductivo, o sea, partiendo del contenido de las normas particulares con el fin de construir conceptos siempre más generales, y clasificaciones o divisiones de todo el material jurídico (Bobbio, 1997).

La tercera significación, alejada ampliamente de las anteriores, considera que el ordenamiento jurídico constituye un sistema porque en él no pueden coexistir normas incompatibles, existiendo bajo este entendido en dicha significación una equivalencia entre el concepto de 
sistema y la validez del principio que excluye la incompatibilidad de las normas (Bobbio, 1997, p.183).

De las anteriores significaciones expuestas, a consideración del autor italiano es la tercera no solo la más interesante, sino aquella que proporciona los cimientos conceptuales más idóneos para una evaluación teórica precisa de la coherencia entre sí de las normas jurídicas que conforman el ordenamiento, que da razón de si efectivamente un ordenamiento no solo tiende sino que se configura efectivamente como sistema.

Es en el marco de estudio del sistema desde la tercera significación y en relación directa al tratamiento teórico evaluativo de la coherencia del ordenamiento jurídico efectuada por Bobbio en el desarrollo de su Teoría del Ordenamiento Jurídico, que el jurista italiano aborda el estudio de las antinomias normativas. En tanto, para comprobar la existencia del principio que excluye la incompatibilidad que fundamenta la tercera significación de sistema, se debe estudiar de qué forma se solventan o corrigen las incompatibilidades que surgen en un ordenamiento cuando dos normas pertenecientes a él son incompatibles entre sí.

Es de esta manera como el estudio del problema de las antinomias normativas se justifica dentro del proceso de construcción de una Teoría del Ordenamiento Jurídico por parte de Bobbio.

\section{CONCEPTO DEANTINOMIA}

Desde la Teoría General del Derecho de Norberto Bobbio (1997) se entiende por antinomia jurídica aquella situación acaecida cuando dos normas jurídicas, pertenecientes a un mismo ordenamiento jurídico y con un ámbito de validez (temporal, espacial, personal o material) igual, son incompatibles entre sí, sucediendo dicha situación cuando una de ellas obliga y la otra prohíbe, o cuando una obliga y la otra permite, o cuando una prohíbe y la otra permite un mismo comportamiento.

El concepto de antinomia ofrecido por Bobbio ofrece al presente escrito un referente conceptual preciso, claro y suficiente de lo que se entiende por antinomia en el ámbito jurídico. Este hecho permite no solo el desarrollo posterior del estudio sobre las antinomias, sino que así mismo facilita el entendimiento del lector sobre dicho tema. 


\subsection{Tipología de las antinomias jurídicas.}

Haciendo uso extensivo de la terminología elaborada por el profesor Alf Ross, Bobbio (1997) elabora una detallada tipología de las antinomias jurídicas teniendo como parámetro de diferenciación la mayor o menor extensión de la contradicción entre las dos normas involucradas en la configuración de la antinomia jurídica.

A partir de dicho parámetro Bobbio reconoce las siguientes antinomias:

- Total-total: Se configura este tipo de antinomia cuando las dos normas incompatibles tienen el mismo ámbito de validez. En ningún caso una de las dos normas puede aplicarse sin entrar en conflicto con la otra. (Bobbio, 1997, p.189).

- Parcial-parcial: Se configura este tipo de antinomia cuando las dos normas incompatibles tienen un ámbito de validez en parte igual y en parte diverso, existiendo antinomia solo en aquellas partes que tengan en común. ( Bobbio, 1997, p.189).

- Total-parcial: Este tipo de antinomia se configura cuando de las dos normas incompatibles una tiene un ámbito de validez igual al de la otra, pero más restringido, es decir, su ámbito de validez es en parte igual y en parte diverso con relación a la otra.

\subsection{Consideraciones teóricas sobre la resolución de antinomias}

La conceptualización, caracterización y tipificación de las antinomias anteriormente desarrolladas son procesos que permiten el reconocimiento de antinomias en un ordenamiento jurídico específico; sin embargo, para que el tratamiento de las antinomias se entienda completo posterior a la determinación o reconocimiento de estas, y para efecto de la búsqueda y establecimiento de mecanismos efectivos de garantía y aseguramiento de la cohesión de un ordenamiento, es pertinente pasar a estudiar las consideraciones teóricas que sobre la resolución de antinomias que Norberto Bobbio pone de presente en el desarrollo de su Teoría del Ordenamiento Jurídico.

Las consideraciones teóricas a continuación expuestas sobre la resolución de antinomias a partir del pensamiento del jurista italiano, tienen como propósito pedagógico ofrecer al lector un referente teórico, preciso y claro, de los parámetros y reglas que orientan la construcción 
teórica positiva de soluciones a la problemática de la existencia de antinomias. Se tiene como objetivo que posterior al estudio de dichas consideraciones, éstas se erijan como el referente teórico orientador de la construcción de consideraciones frente a la resolución especifica de la antinomia objeto de estudio en el presente documento descrita con precisión en el ejemplo contenido en páginas posteriores.

\section{CRITERIOS JURISPRUDENCIALES Y DISTINCIÓN PRELIMINAR.}

En la primera instancia de su disertación teórica frente a la resolución de antinomias, Norberto Bobbio expone que derivado del estudio del desarrollo interpretativo de las normas jurídicas llevado a cabo en el ámbito jurisprudencial, la comunidad jurídica ha logrado establecer un conjunto de parámetros o reglas para la resolución de antinomias. Dichos parámetros o reglas son:

- El criterio cronológico: Es aquel criterio a partir del cual frente a dos normas incompatibles prevalece la posterior. Dicho criterio fundamenta su existencia en la regla general del derecho que reconoce que la voluntad posterior deroga la anterior, y así mismo en aquella que reconoce que de dos actos de una misma persona, es válido entre ellos el último en el tiempo. (Bobbio, 1997, p.192).

- El criterio jerárquico: Es aquel criterio a partir del cual frente a dos normas incompatibles prevalece la superior. (Bobbio, 1997, p.192). Fundamentado en la estructura jerárquica del ordenamiento jurídico estudiando y caracterizado en el estudio teórico del derecho, dicho criterio busca dirimir la incompatibilidad entre normas haciendo prevalecer el poder normativo de una norma jerárquicamente superior frente a una que le sea jerárquicamente inferior a esta.

- El criterio de especialidad: Es aquel criterio con base en el cual entre dos normas incompatibles, la una general y la otra especial prevalece la segunda. Se comprende que la ley especial debe prevalecer sobre la general, porque la norma especial representa un momento que no se puede eliminar en el desarrollo de un ordenamiento jurídico. (Bobbio, 1997, p. 195)

Pese a su pertinencia e idoneidad teórica Bobbio deja en claro que dichos parámetros o reglas no son útiles para la resolución de la totalidad de los casos de incompatibilidad de normas en un ordenamiento jurídico. 


\subsection{Insuficiencia y conflicto de los criterios jurisprudenciales.}

A partir del reconocimiento de dicha limitación de implementación, un nuevo tipo de clasificación puede ser referido a las antinomias. Así, las antinomias que acaecen en un ordenamiento jurídico pueden ser solubles o insolubles, es decir, pueden ser solucionables a partir de la implementación de los parámetros de resolución de las mismas de reconocimiento común y desarrollo jurisprudencial, o pueden ser insolucionables, ya sea por la inaplicación de criterios o por la posibilidad de aplicación de dos o más criterios contrarios entre sí.

Frente a la insuficiencia de los criterios para dar solución a una antinomia, Bobbio plantea la posibilidad de uso de un cuarto criterio, conocido como criterio de forma, que resuelve la antinomia enfrentado las formas de las normas en conflicto (imperativas, prohibitivas y permisivas) dando prevalencia a una de ellas en atención a la prevalencia de su forma y a la idoneidad de su aplicación frente al caso concreto. Sin embargo, las soluciones efectuadas a partir del criterio de forma no cuentan con el carácter vinculante que cuentan aquellas efectuadas con los tres criterios inicialmente formulados, pues el criterio de forma no está jurisprudencialmente acogido en tanto que es un criterio rescatado de las practicas efectuadas por los antiguos juristas para dirimir conflictos entre normas.

Al no poseer efectos vinculantes concretos, el criterio de forma no resulta idóneo para la resolución de antinomias para cuya solución no resulta suficiente la aplicación de alguno de los criterios vinculantes. Frente a dicho escenario de insuficiencia de criterios, Bobbio es preciso en aclarar que derivada de dicha insuficiencia la solución de antinomias insolubles es confiada al poder discrecional del intérprete (juzgador o jurista). Este debe llegar a una determinación que dé solución al conflicto normativo deberá valerse de todas las técnicas hermenéuticas adoptadas por la tradición jurídica, sin hacer excluyente su aplicación.

En concreto, Bobbio (1997, p. 198) reconoce en dicho escenario tres posibilidades de resolución de la antinomia:

- Eliminar una de las normas: Comporta la ejecución de una interpretación abrogante impropia, pues aunque se excluya una norma para la resolución de un caso específico no se descarta la norma propiamente del ordenamiento jurídico. 
- Eliminar las dos: Posibilidad ejecutable de manera exclusiva en el escenario en que dos normas sean contradictorias. Comporta la ejecución de una doble abrogación impropia.

- Conservar las dos: Implica la ejecución de una interpretación de carácter correctivo, entendida esta como aquella forma de interpretación que pretende conciliar dos normas aparentemente incompatibles para conservarlas ambas en el sistema, o sea para evitar la abrogación (Bobbio, 1997, p. 200). Con ella lo que se busca no es propiamente eliminar una norma, sino eliminar una incompatibilidad aparente derivada de una interpretación errónea, unilateral o incompleta de las normas.

En caso de que la corrección implique una modificación del texto original de una norma podría presentarse una abrogación atenuada.

Dicha posibilidad es la de mayor aplicación, en tanto que juristas y jueces propenden comúnmente por la conservación de las normas dadas (Bobbio, 1997, p. 201). Adicionalmente debe comprenderse que antes de una interpretación abrogante, tanto el jurista como el juez deben propender por la implementación de una interpretación correctiva que permita la conservación de las normas del ordenamiento jurídico.

Abordada la insuficiencia de criterios, es procedente abordar el conflicto que se deriva de éstos, que constituye la segunda razón por la que una antinomia puede ser calificada como insoluble.

Frente al conflicto de criterios expresa Bobbio (1997) que dicho fenómeno puede acaecer cuando a dos normas incompatibles entre sí y que se encuentran en una determinada relación, se les puede aplicar más de un criterio y la aplicación de éstos genera resultados contrarios, resultando una incompatibilidad de de los mismos. Los conflictos de criterios pueden ser tres:

- Conflicto entre el criterio jerárquico y el criterio cronológico: Conflicto acaecido entre una norma anterior - superior y una posterior - inferior. La aplicación del criterio jerárquico resuelve la antinomia en favor de la norma anterior - superior y la aplicación del criterio cronológico ofrece una solución contraria. En atención al principio del orden jerárquico que orienta la configuración del ordenamiento jurídico, el conflicto entre criterios es resuelto en favor de la aplicación del criterio jerárquico. 
- Conflicto entre el criterio de especialidad y el criterio cronológico: Conflicto acaecido entre una norma anterior - especial y una posterior - general. La aplicación del criterio de especialidad resuelve la antinomia en favor de la norma anterior - especial y la aplicación del criterio cronológico ofrece una solución contraria. Por regla establecida el conflicto de criterios es resuelto en favor de la aplicación del criterio de especialidad; sin embargo, dicha regla no es absoluta y la resolución de esta tipología de conflicto entre criterios debe ser evaluada a partir de los casos concretos.

- Conflicto entre el criterio jerárquico y el criterio de especialidad: Conflicto acaecido entre una norma superior - general y una inferior - especial. La aplicación del criterio de especialidad resuelve la antinomia en favor de la norma inferior - especial y la aplicación del criterio jerárquico ofrece una solución contraria.

En dicho conflicto se ven enfrentados implícitamente los principios de respeto al ordenamiento jurídico y el principio de justicia y especialidad del derecho, hecho que amplifica la dificultad de su resolución.

A consideración de Bobbio, la resolución del presente conflicto de criterios debe quedar a consideración del juez de conformidad con cada caso específico, aclarando que aunque teóricamente debe prevalecer la norma superior sobre la inferior, el derecho debe dirigirse siempre hacia la especialidad en su aplicación.

\subsection{Coherencia del ordenamiento como deber.}

Bobbio (1997) también se cuestiona sobre el poder vinculante del deber de coherencia del ordenamiento jurídico en la actividad de legisladores y jueces en distintos escenarios antinómicos.

El primer escenario en el que Bobbio cuestiona la existencia de un deber real y jurídico de coherencia del ordenamiento es el de existencia de normas contrarias de diferente nivel jerárquico. En dicho escenario el jurista italiano advierte que frente a la actividad legislativa el deber de coherencia se materializa en la regla que ordena a las personas u órganos que producen normas inferiores, producir normas que no sean contrarias a las normas superiores (Bobbio, 1997, p. 205). Por su parte, frente a la actividad judicial advierte que el deber se materializa en la regla que orienta al juez a que en caso de un conflicto entre dos normas de diferente jerarquía debe aplicar la norma superior. 
El segundo escenario por su parte es el de existencia de normas contrarias de igual nivel y sucesivas en el tiempo. En dicho escenario el deber no es expresable por regla alguna en la actividad legislativa, dando libertad a la contradicción en la actividad creadora del legislador, hecho que le traslada la salvaguarda de la coherencia del ordenamiento jurídico al juez, quien en su actividad judicial frente a un conflicto de normas de dicha naturaleza deberá aplicar la norma posterior.

El tercer escenario es el de normas del mismo nivel y contemporáneas. En este escenario el deber de coherencia no es expresable en ninguna regla vinculante ni para el legislador en su actividad legislativa, ni para el juez en su actividad judicial, pues éste será guiado únicamente por una necesidad de hecho frente a la cual decidirá aplicar una norma e inaplicar la otra de conformidad a como lo crea procedente en cada caso específico. El deber es entonces, a consideración de Bobbio, estrictamente moral.

Del último escenario Bobbio aclara que se podría concluir entonces que una ley contradictoria es válida, y al serlo, las dos normas contradictorias en ella también lo son.

Dicha aclaración merece una atención especial, pues el mismo Bobbio ofrece este ejemplo para cuestionar a la compatibilidad como un requisito de la validez de una norma jurídica, pues en el tercer escenario planteado aunque las normas son incompatibles su validez no se afecta. Frente a ello, concluye el teórico que al menos para el tercer escenario la compatibilidad no es un requisito para la validez de la norma, sin embargo, debe serlo para la justicia del ordenamiento jurídico, pues la compatibilidad es un requisito fundamental para el alcance de certeza y justicia en la aplicación de normas jurídicas contenidas en el ordenamiento.

Con dicha conclusión, Bobbio concluye su esfuerzo teórico frente a la configuración de modelos y criterios para la resolución de antinomias, entendiendo siempre la existencia de estas como un perjuicio para la coherencia del ordenamiento jurídico. Como tal se debe propender siempre por ser eliminado incluso cuando no exista modelo de solución alguno para su resolución.

\section{EL CASO HIPOTÉTICO: ¿LA ANTINOMIA EXISTENTE?}

Se procede a abordar, con los recursos teóricos provistos por la Teoría General del Derecho del jurista italiano, el tratamiento de la antinomia que motiva la ejecución de la presente investigación a través del estudio 
un caso hipotético, que una vez planteado en la parte introductoria de este escrito ahora, procederá a ser formulado y resuelto en una instancia preliminar a modo de hipótesis haciendo uso de los postulados teóricos sobre resolución de antinomias del mismo Bobbio. Dicha resolución preliminar a modo de hipótesis, cabe aclarar, se realiza como un ejercicio académico de materialización de la teoría del autor italiano a una antinomia concreta acaecida en el ordenamiento jurídico colombiano ${ }^{2}$.

\subsection{El caso hipotético.}

- Arturo González en su condición de empleado público de carrera administrativa produce una serie de daños a unos particulares con la expedición de un acto administrativo.

- Aquellos inician un proceso contencioso administrativo en contra de la entidad pública a la que Arturo González prestaba sus servicios, en el que demuestran la ilegalidad de dicho acto administrativo e ilicitud de su actuar, y obtienen una sentencia favorable a sus pretensiones, en la que se reconoce a su favor una suma de varios millones de pesos.

- Luego de pagar esta condena pecuniaria, aquella entidad pública inicia un proceso de repetición en contra de Arturo González quien pocos meses atrás se había desvinculado del servicio público.

- En dicho proceso, esta entidad logra probar que el daño antijurídico que tuvo que indemnizar fue ocasionado por una conducta gravemente culposa de Arturo González, quien es condenado a reembolsar el dinero que salió del erario.

- Dicha condena salió días antes de que Arturo González fuera elegido Congresista, saliendo a la luz pública cuando ya había tomado posesión de su cargo.

- Ante esta situación se presenta una demanda en la que se solicita la pérdida de la investidura como congresista de Arturo González por la transgresión de la inhabilidad prevista en el inciso final del artículo 122 de la Constitución de 1991.

- El mismo día en que Arturo González es notificado de la admisión de la demanda de pérdida de investidura, paga la condena patrimonial a la entidad pública afectada. 


\subsection{La antinomia existente.}

El Consejo de Estado, juez competente para resolver la solicitud de pérdida de investidura tendría que aplicar dos normas:

a) El artículo 183.1 de la Constitución de 1991, regla que establece como consecuencia jurídica la pérdida de investidura de congresista de quien haya violado su régimen de inhabilidades. Esta regla resulta aplicable a su vez por la transgresión de la inhabilidad prevista en el inciso final del artículo 122 que prohíbe, entre otras, ser elegido a un cargo público a "quien haya dado lugar, como servidor público, con su conducta dolosa o gravemente culposa, así calificada por sentencia judicial ejecutoriada, a que el Estado sea condenado a una reparación patrimonial"

b) La excepción a la inhabilidad del artículo 122 que hace superable la inhabilidad cuando quién generó la condena al Estado asume "con cargo a su patrimonio el valor del daño". Esta excepción puede edificarse como una regla con un operador deóntico de permisión que habilita el ejercicio de los derechos políticos.

La antinomia, como se advirtió al inició de este escrito, se deriva en que si se aplicara la sanción de la pérdida de investidura -toda vez que la transgresión a la inhabilidad del artículo 122 se materializó completamente- ello se constituye en la muerte política de Arturo González, pues a perpetuidad no podría acceder de nuevo a ningún cargo de elección popular. Por el contrario, si aplicara la excepción del artículo 122 constitucional, que habilita el pleno ejercicio de derechos fundamentales políticos, bien podría no decretarse la pérdida de investidura.

Así pues, cada curso de decisión posible implica no dar eficacia a la regla contraria. El Consejo de Estado podría: o edificar una sanción perpetúa a partir de una inhabilidad temporal y superable, o no derivar la pérdida de la investidura pese a que se ha desconocido una inhabilidad constitucional.

\subsection{Resolución hipotética de la antinomia existente a partir de las consideraciones teóricas de Norberto Bobbio}

\section{Caso que deriva en la configuración de una relación de incompatibilidad entre normas}

Una norma prohíbe y la otra permite un mismo comportamiento en apariencia. Ambas poseen el mismo ámbito de validez espacial, temporal y personal. 


\section{Caracterización de las normas en conflicto}

NormaA

ARTICULO 183. Los congresistas perderán su investidura: 1. Por violación del régimen de inhabilidades e incompatibilidades, o del régimen de conflicto de intereses. 2. Por la inasistencia, en un mismo período de sesiones, a seis reuniones plenarias en las que se voten proyectos de acto legislativo, de ley o mociones de censura.

3. Por no tomar posesión del cargo dentro de los ocho días siguientes a la fecha de instalación de las Cámaras, o a la fecha en que fueren llamados a posesionarse.

4. Por indebida destinación de dineros públicos.

5. Por tráfico de influencias debidamente comprobado.

PARÁGRAFO. Las causales 2 y 3 no tendrán aplicación cuando medie fuerza mayor.

La primera norma Art. 183 C.N numeral $1^{\circ}$, denominada a partir de ahora para efectos de la facilidad de su tratamiento como norma $\mathbf{A}$, es un mandato de carácter prohibitivo, de nivel o jerarquía constitucional, contenida en la Constitución Política de Colombia de 1991 y por lo tanto se entiende elaborada en dicho año.

\section{Norma B}

ARTICULO 122. No habrá empleo público que no tenga funciones detalladas en ley o reglamento, y para proveer los de carácter remunerado se requiere que estén contemplados en la respectiva planta y previstos sus emolumentos en el presupuesto correspondiente

Ningún servidor público entrará a ejercer su cargo sin prestar juramento de cumplir y defender la Constitución y desempeñar los deberes que le incumben.

Antes de tomar posesión del cargo, al retirarse del mismo o cuando autoridad competente se lo solicite deberá declarar, bajo juramento, el monto de sus bienes y rentas.

Dicha declaración sólo podrá ser utilizada para los fines y propósitos de la aplicación de las normas del servidor público. 
Modificado por el art. 4, Acto Legislativo 01 de 2009. El nuevo texto es el siguiente: Sin perjuicio de las demás sanciones que establezca la ley, no podrán ser inscritos como candidatos a cargos de elección popular, ni elegidos, ni designados como servidores públicos, ni celebrar personalmente, o por interpuesta persona, contratos con el Estado, quienes hayan sido condenados, en cualquier tiempo, por la comisión de delitos que afecten el patrimonio del Estado o quienes hayan sido condenados por delitos relacionados con la pertenencia, promoción o financiación de grupos armados ilegales, delitos de lesa humanidad o por narcotráfico en Colombia o en el exterior.

Tampoco quien haya dado lugar, como servidores públicos, con su conducta dolosa o gravemente culposa, así calificada por sentencia ejecutoriada, a que el Estado sea condenado a una reparación patrimonial, salvo que asuma con cargo a su patrimonio el valor del daño.

Por su parte, la segunda norma Art. 122 C.N inciso final, denominada a partir de ahora para efectos de la facilidad de su tratamiento como norma $\mathbf{B}$, es un mandato de carácter permisivo, de nivel o jerarquía constitucional, contenida en la Constitución Política de Colombia de 1991, cuyo texto responde a la modificación realizada por Acto Legislativo 01 de 2004, por lo que se entiende configurada en el año 2004, pese a encontrarse inicialmente creado el art. 122 C.N en el año de 1991.

Como inhabilidad se "refiere a ciertas circunstancias personales previas de carácter permanente o transitorio que hacen que un ciudadano sea inelegible para desempeñar" (Díaz, 1992, p. 383) el cargo de congresista. Su finalidad es que solo los mejores ostenten la dignidad de congresista y "son una garantía de que el comportamiento anterior o el vínculo familiar no afectarán el desempeño del empleo" (Cardoso, Padrón, Rizo y Salguero, 2015).

A través de esta norma se restringen dos facetas del derecho a ser elegido o sufragio pasivo: el "derecho de acceso al cargo de elección popular", esto es "el derecho a presentarse como candidato a las elecciones populares", y el "derecho a ser proclamado electo", que exige "la efectiva proclamación de aquellos candidatos que resultaron elegidos" (Vanegas, 2009, pp. 55 a 56), este último evento se da, por ejemplo, 
cuando luego de la inscripción y antes de la elección sobreviene la condena de acción de repetición.

\section{Tipo de antinomia.}

Antinomia Total- Total: Ámbitos de validez temporal, espacial y personal iguales.

Antinomia aparente por interpretación incompleta de las normas en estudio.

\section{Consideraciones preliminares.}

\section{Inscripción de una candidatura.}

La Registraduría Nacional del Estado Civil (2015) define la inscripción de una candidatura como:

El acto voluntario con el que el candidato adquiere un compromiso político y jurídico con la sociedad. Los ciudadanos que aspiren a participar como candidatos en las elecciones de Congreso, Parlamento Andino, Presidente y Vicepresidente de 2014, deberán inscribir sus nombres en las condiciones y términos establecidos por la Ley.

Así mismo, deja en claro los medios a través de los cuales un particular puede inscribir su candidatura, en el siguiente tenor:

Un candidato se puede inscribir con el aval de un partido o movimiento político con personería jurídica reconocida por el Consejo Nacional Electoral o con el apoyo de un grupo significativo de ciudadanos, caso en el que se requiere aportar el total de firmas correspondiente y la póliza de seriedad.

\section{Perdida de investidura.}

La pérdida de investidura constituye la máxima sanción política disciplinaria del congresista. En referencia a su origen, citando taxativamente lo considerado por el Consejo de Estado, frente al altísimo nivel de responsabilidad del congresista, que es único en el Estado Social de Derecho y no lo comparten otros servidores públicos, el constituyente sanciona con la perdida de investidura aquellas conductas 
que atentan contra la dignidad parlamentaria, como lo es por ejemplo la violación del régimen de inhabilidades, incompatibilidades y conflicto de interés del Congresista ${ }^{3}$.

En referencia a los efectos de la imposición de la perdida de investidura es procedente decir que los efectos de la sanción son perpetuos, implicando no solamente la separación definitiva, permanente y vitalicia de la calidad de congresista sino así mismo la muerte política para el particular, traducida en la inhabilidad a perpetuidad para ejercer cargos de elección en el futuro T-1285 de 2005).

Henao (2003) señala que el diseño del constituyente de la pérdida de investidura como sanción no incluye el criterio de graduación o proporcionalidad, pues en todo caso, sin importar las condiciones objetivas y subjetivas en las que se incurre en la inhabilidad, se obtiene la misma decisión.

La pérdida de investidura tiene entre otros como objeto garantizar, a través de la imposición de una estricta sanción, el respeto del régimen de inhabilidades, incompatibilidades y conflicto de intereses; es un control a la actividad parlamentaria, realizada desde fuera del órgano legislativo que procura "la ausencia de impunidad de los congresistas" (Porto, 2002, p. 575).

Las causales que dan lugar a la declaratoria por parte del Consejo de Estado, tribunal competente para el conocimiento de la acción de pérdida de investidura (art. 184 y 237-5 Constitución Política) se encuentran consagradas en el art. 183 de la Constitución.

En relación concreta a la causal primera del art. 183 C.N, objeto de estudio de la presente investigación, es posible decir que esta se encuentra redactada de manera general, refiriéndose en abstracto a las inhabilidades, incompatibilidades y conflictos de intereses que por mandato constitucional pueden recaer al congresista y no de manera específica a las consagradas en el art. 180 y 181 C.N, pues pese a encontrarse ubicada en el denominado Estatuto del Congresista, este así mismo se encuentra contenido en la Constitución Política de Colombia, que desde una interpretación sistemática, no solo consagra para los congresistas las inhabilidades del art. 180, sino así mismo, por ejemplo, las derivadas del articulo 122 C.N, pues el cargo de congresista es un cargo de elección popular; y el art. 122 prohíbe la inscripción a una

3 Para efectos del presente estudio cabe sentar claridad en que el congresista es un funcionario público elegido por votación popular miembro de una corporación pública de elección popular 
candidatura a un cargo de elección popular, como el de congresista, a la persona que siendo servidor público hubiese dado lugar con su conducta dolosa o gravemente culposa, así calificada por sentencia ejecutoriada, a que el Estado sea condenado a una reparación patrimonial, solo pudiendo inscribir su candidatura al Congreso de la República en el escenario en que asuma con cargo a su patrimonio el valor del daño.

De lo anterior se deriva que, adicional a lo expresado en el art. 183 C.N, tampoco podrá ser congresista quien habiendo sido servidor público y en el ejercicio de sus funciones hubiese dado lugar con su conducta dolosa o gravemente culposa, así calificada por sentencia ejecutoriada, a que el Estado sea condenado a una reparación patrimonial, y el Estado hubiese repetido contra él, este hubiese sido condenado a pagar al Estado el valor del daño y no lo hubiese pagado.

Ahora bien, respecto a la inhabilidad para personas naturales referida del art. 122 C.N, cabe decir que a partir del pronunciamiento de la Corte Constitucional de Colombia en sentencia C-630 de 2012, en la que se hace una recopilación de pronunciamientos jurisprudenciales afines a la temporalidad de las inhabilidades del art. 122, debe entenderse que las inhabilidades del art. 122, entre ellas la de ser inscrito o elegido a cargo de elección popular, tienen un carácter intemporal:

4.4.3. En síntesis, la propia Constitución establece la naturaleza intemporal de las inhabilidades consagradas en su artículo 122. En tal sentido, la jurisprudencia constitucional ha reiterado el carácter permanente de ellas, al punto que, por no tratarse de sanciones punitivas, hasta el Legislador puede establecerlas de no existir objeción constitucional.

Sin embargo, el mismo artículo 122 C.N plantea una excepción a dicha intemporalidad. La excepción se configura en el supuesto fáctico de haber dado lugar el servidor público, por conducta dolosa o gravemente culposa, a condena judicial de reparación patrimonial contra el Estado, en el cual la inhabilidad para ser inscrito o elegido a cargo de elección popular, ser designado servidor público y celebrar contratos con el Estado (directamente o por persona interpuesta) derivadas de la configuración de dicho supuesto, cesan o dejan de existir cuando el particular paga la suma a la que ha sido condenada en la acción de repetición promovida por el Estado contra el por el detrimento patrimonial causado a este. De tal modo, solo el pago acaba con dicha inhabilidad y permite, para el caso concreto, poder ser inscrito o elegido a cargo de elección popular. 
Finalmente, habiendo dejado en claro la intemporalidad de las inhabilidades del art. 122 C.N, la procedencia de una excepción a dicha intemporalidad y la forma en que esas inhabilidades tienen cabida dentro de las inhabilidades cuya violación el art. 183 contempla como causal de procedencia de la perdida de investidura a un congresista a partir de una interpretación sistemática, cabe formular entonces el siguiente cuestionamiento formulado en la introducción de este texto: ¿puede en sancionarse con la pérdida de la investidura de congresista a quien llega a tal dignidad transgrediendo la prohibición del inciso final del artículo 122 constitucional?

La resolución de dicho cuestionamiento se llevara a cabo desde dos interpretaciones consideradas por Bobbio como posibles, una interpretación correctiva y una interpretación abrogante. A continuación se procederá entonces a desarrollarlas.

\section{Resolución hipotética.}

\section{Interpretación correctiva.}

Anterior a la ejecución de una interpretación abrogativa de la cual se derive la eliminación o supresión de una de las normas en conjunto, procede estudiarse la posibilidad de la resolución de la antinomia desde una interpretación correctiva del caso, por medio de la cual se logre conciliar las dos normas aparentemente incompatibles para conservarlas ambas en el sistema.

Con ella lo que se busca no es propiamente eliminar una norma, sino eliminar una incompatibilidad aparente derivada de una interpretación errónea, unilateral o incompleta de las normas.

Desde una interpretación correctiva debe dejarse en claro la diferencia existente entre la superación de una inhabilidad y la superación o eliminación de una violación a un régimen de inhabilidades.

La superación de una inhabilidad es un hecho jurídicamente permitido condicionado al cumplimiento de una condición o presupuesto. La inhabilidad para inscribirse a un cargo de elección popular del art. 122 incisos $6^{\circ}$ es una inhabilidad superable (la única cuyo carácter no es absolutamente intemporal) a través del pago de la condena, es decir, que un particular que desee inscribir su candidatura al Congreso de la República y se encuentre inhabilitado porque como servidor público que fue en el pasado dio lugar, con su conducta dolosa o gravemente culposa, 
así calificada por sentencia ejecutoriada, a que el Estado fuera condenado a una reparación patrimonial, puede superar dicha inhabilidad pagando el valor del daño causado, teniendo como efecto jurídico la habilitación inmediatamente posterior al pago para que inscriba su candidatura.

Por otro lado, es totalmente distinta la superación de una violación al régimen de inhabilidades. Contraria a la superación de una inhabilidad, no existe norma o pronunciamiento en concreto en el ordenamiento jurídico colombiano que permita profesar la viabilidad jurídica de la superación de una violación manifiesta del régimen de inhabilidades o incompatibilidades.

Frente a la inhabilidad referida del artículo 122 C.N cabe aclarar que el pago del valor del daño al que se le condena a particular en la acción de repetición promovida por el Estado jurídicamente, por mandato de la misma norma, hace procedente la superación de la inhabilidad, siempre y cuando dicho pago se efectué con anterioridad a la inscripción de la candidatura al cargo de elección popular (congresista para el caso específico); sin embargo, nada obsta para que se haga extensiva dicha procedencia a una superación de la inhabilidad posterior a la inscripción de la candidatura, pues si el particular inscribe su candidatura debiendo el pago del valor del daño configura ya en ese momento una violación manifiesta a la prohibición del mismo artículo 122 C.N, es decir, configura una violación al régimen constitucional de inhabilidades para acceder a un cargo de elección popular (congresista).

Como se expresó anteriormente, en el ordenamiento jurídico colombiano no existe norma o pronunciamiento alguno que permita deducir la viabilidad jurídica de la superación de una violación manifiesta del régimen de inhabilidades específicamente, como la que configuraría un particular si inscribe su candidatura a congresista sin haber superado con el pago la inhabilidad del art. 122 C.N, expresándose solamente frente a la configuración de dicha violación las sanciones procedentes. En el caso del congresista, la sanción procedente frente a la violación del régimen constitucional de inhabilidades para acceder a dicho cargo es la perdida de investidura, de conformidad como se ha referenciado anteriormente al artículo 183 C.N numeral $1^{\circ}$.

Ahora bien, teniendo en cuenta que la violación del régimen de inhabilidades constitucionales para acceder al cargo de congresista bajo los presupuestos del art. 122 C.N inciso $6^{\circ}$ se configura desde el momento en que, inhabilitado el particular por adeudar al Estado (quien 
fuera condenado a una reparación patrimonial y promovió acción de repetición en su contra) el pago de la suma de un daño que como servidor público que fue en el pasado dio lugar, con su conducta dolosa o gravemente culposa, así calificada por sentencia ejecutoriada, éste inscriba su candidatura al Congreso de la República de Colombia, es procedente afirmar que dicha violación es intemporal, es decir, tiene efectos perpetuos, por lo que en el escenario en que dicho particular sea elegido y posesionado como congresista, dicha violación le seguirá impidiendo jurídicamente serlo aun cuando pague la suma del daño adeudada al Estado, pues como ya se dijo, el pago posterior a la inscripción estando inhabilitado por causal del art. 122 C.N de la candidatura, no anula la inhabilidad porque allí ya se ha configurado es una violación a una inhabilidad precedente a la inscripción misma.

Lo anterior quiere decir entonces que no importa si el particular, ahora posesionado como congresista, paga la suma adeudada al Estado posterior a su inscripción o posterior a su posesión, de igual manera le seguirá siendo jurídicamente viable la imputación de una violación al régimen de inhabilidades constitucionales para acceder al cargo de congresista por haber inscrito su candidatura estando inhabilitado. Puede, por tanto, ser objeto de la imposición de la sanción respectiva por dicha violación, que en su condición de congresista no es otra que la perdida de investidura por mandato del art. 183 C.N causal $1^{\circ}$.

La anterior interpretación es, desde las consideraciones teóricas sobre la resolución de antinomias de Norberto Bobbio, una interpretación de carácter correctiva, en tanto que ofrece una interpretación completa y plurilateral de la incompatibilidad aparente entre las normas A y B que motiva el presente estudio, salvaguardando la permanencia de las normas evitando la abrogación de alguna de ellas.

Como conclusión cabe afirmar entonces que desde esta interpretación, es procedente sancionar con la perdida de investidura al congresista que hubiese llegado a dicho cargo transgrediendo la prohibición del inciso final del artículo 122 constitucional, pues como ya se vio, dicha prohibición constituye una causal de inhabilidad constitucional para ser congresista. Quiere esto decir que su desatención comporta una violación al régimen de inhabilidades constitucionales para acceder a dicho cargo, dicha violación, tiene efectos perpetuos, es decir no posee excepción expresa alguna que permita su supresión o eliminación, y por ende al ostentar el particular la condición de congresista y habiendo llegado allí configurando dicha violación, cumple con el presupuesto 
factico del art. 183 numeral $1^{\circ}$ dando lugar a la aplicación de dicha norma, es decir, a la sanción de su conducta con la perdida de la investidura como congresista.

\section{Interpretación abrogante.}

La interpretación abrogante comporta la supresión de la aplicación de una norma para la solución de una incompatibilidad entre dos normas (normas A y B). Dicha supresión debe encontrarse debidamente fundamentada, es decir, debe sustentarse en la aplicación de un criterio o parámetro objetivo debidamente reconocido. En adición a lo anterior, la supresión de una norma debe responder no solamente a la solución efectiva de la incompatibilidad, sino así mismo debe respetar el principio de justicia del ordenamiento jurídico y asegurar la coherencia del mismo.

Estudiadas desde los criterios objetivos reconocidos por Norberto Bobbio para la resolución de antinomias, es procedente decir que desde el criterio jerárquico ambas normas poseen el mismo nivel. Por su parte, desde el criterio cronológico la norma B (art. 122 C.N inciso final) es posterior a la norma $\mathrm{A}$, pues la norma $\mathrm{B}$ es producto de una modificación al artículo 122 de la Carta política efectuada en el año 2004 por el Acto Legislativo 01 de ese año, mientras que la norma A (art. 183 numeral $1^{\circ}$ ) existe desde el año 1991 con la promulgación misma de la Carta Política. Así mismo, desde el criterio de especialidad la norma B resulta especial frente a la norma A general, en tanto que la norma B consagra con detalle un presupuesto factico detallado que da lugar a una consecuencia jurídica, mientras que la norma A ofrece un presupuesto general para la aplicación de la perdida de investidura, sin especificar de ningún modo las inhabilidades, incompatibilidades o los conflictos de interés que componen dicho régimen.

Derivado de dicha caracterización se concluye entonces que la norma B es posterior-especial frente a la norma A que es anterior-general.

Cabe recordar que de conformidad con lo plateado por Bobbio la norma especial prevalece sobre la general y la norma posterior sobre la anterior.

Es importante notar que en el presente caso no se configura conflicto de criterios, sino que por el contrario, tanto desde el criterio cronológico como desde el criterio de especialidad la norma B prevalece sobre la normaA. 
La anterior conclusión supone entonces que para la resolución del presente caso deben aplicarse prevalentemente las disposiciones de la norma $\mathrm{B}$ abrogando las disposiciones de la norma $\mathrm{A}$, implicando que sea jurídicamente viable que el congresista pueda alegar el pago del valor de la sanción para como acto por medio del cual se logra superar la inhabilidad del inciso final. Con esto se puede entender como superada $o$ inexistente la violación al régimen de inhabilidades que motiva la solicitud de imposición de la sanción de pérdida de su investidura como congresista, dejando sin fundamento la procedencia de la sanción.

Sin embargo, dicha resolución presenta algunos inconvenientes:

- La interpretación de las disposiciones del art. 122 C.N inciso final, efectuadas desde dicha resolución, hace extensivos los efectos jurídicos del pago de la suma adeudada al Estado por un daño causado que este debió pagar a la superación de la violación de la causal de inhabilidad, cuando dicha extensión no se encuentra reconocida en el ordenamiento jurídico colombiano. Hay claridad en que el pago de la suma adeudada al Estado por un daño causado que éste debió pagar, solo da lugar a la superación de la inhabilidad, más en ningún momento da a entender que así mismo a la superación de la violación manifiesta de dicha inhabilidad, configurada con la inscripción de la candidatura al congreso estando inhabitado.

- Así mismo, cabe resaltar desde una perspectiva teórica que la presente no es una antinomia normativa en sentido estricto pues no hay entre las dos normas una contrariedad de mandato, sino es una antinomia aparente derivada de una interpretación incompleta y unilateral de las disposiciones legales de cada una de las normas. Tal condición le permite ser solucionable de forma idónea a través de una interpretación correctiva como la esbozada con anterioridad, en el entendido que permite la garantía efectiva del principio de coherencia del ordenamiento que es el objetivo principal de la resolución de antinomias.

Los anteriores inconvenientes permiten denotar que pese a que la solución de la antinomia es viable no es la jurídicamente idónea, pues carece de una fundamentación teórica y jurídicamente adecuada, en tanto la aplicación de una interpretación abrogante para resolverla no resulta consecuente con la lectura sistemática desde la cual deben ser percibidas las normas que se encuentran dentro de un mismo ordenamiento jurídico. 


\section{CONCLUSIONES}

La incompatibilidad de las normas A y B es aparente, en tanto que sus mandatos no son contrarios o incompatibles sino que en su aplicación al caso específico aparentan estarlo producto de una interpretación incompleta que de estas normas se ha hecho.

El hecho de que la incompatibilidad sea aparente permite la conservación de las dos normas por medio de la elaboración de una interpretación completa y sistemática de las disposiciones de ambas que permita no eliminar una de las normas ellas, sino la incompatibilidad aparente.

La interpretación mediante la cual se logra la conservación de las dos normas derivada de la aclaración de los reales alcances jurídicos de sus contenidos, se denomina interpretación correctiva desde la Teoría del Ordenamiento Jurídico de Norberto Bobbio.

La interpretación correctiva es entonces idónea para la resolución de la incompatibilidad de disposiciones negativas que motiva el presente estudio.

Desde una interpretación correctiva para el caso específico en estudio, es preciso afirmar que es procedente sancionar con la perdida de investidura al congresista que hubiese llegado a dicho cargo transgrediendo la prohibición del inciso final del artículo 122 constitucional. Esto porque dicha prohibición constituye una causal de inhabilidad constitucional para ser congresista, lo que quiere decir que su desatención comporta una violación al régimen de inhabilidades constitucionales para acceder a dicho cargo, dicha violación, tiene efectos perpetuos. No existe excepción expresa alguna que permita su supresión o eliminación, y por ende, al ostentar el particular la condición de congresista y habiendo llegado allí configurando dicha violación, cumple con el presupuesto factico del art. 183 numeral $1^{\circ}$ dando lugar a la aplicación de dicha norma, es decir, a la sanción de su conducta con la perdida de la investidura como congresista.

Teniendo a la interpretación correctiva como la idónea para la resolución de la incompatibilidad en estudio, se toma la conclusión derivada de su ejecución anteriormente expuesta como la respuesta más acertada que desde la teoría de Norberto Bobbio se le puede dar al cuestionamiento sobre la procedencia de la sanción con la pérdida de la investidura de congresista a quien llega a tal dignidad transgrediendo la prohibición del inciso final del artículo 122 constitucional. 


\section{REFERENCIAS BIBLIOGRÁFICAS}

Bobbio, N. (1997). Teoría General del Derecho. Bogotá: Temis.

Cardoso, J, Padrón, A., Rizo, R., \& Salguero, G. (2015). Descentralización y entidades territoriales: inhabilidades e incompatibilidades para los cargos de elección popular a nivel territorial. Bogotá: Instituto de Estudios del Ministerio Público.

Colombia. Consejo de Estado. Sala de Consulta y Servicio Civil. (03 de julio de 2008). C.P. William Zambrano Cetina. Rad.: 11001-03-06-0002008-00029-00(1894). Consultante: Ministerio del Interior Colombia. Corte Constitucional de Colombia. (7 de diciembre de 2005). Sentencia T 1285. M. P. Clara Inés Vargas Hernández.

Colombia. Corte Constitucional de Colombia. (15 de agosto de 2012). Sentencia C. M. P. Mauricio González Cuervo.

Díaz, P. (1993). La Constitución política colombiana (1991). Bogotá: Temis.

Henao, J. (2003). Derecho proceso constitucional. Bogotá: Temis.

Kelsen, H. (2011). Teoría pura del Derecho. México D.F.: Porrúa.

Porto, H. (2002). El proceso constitucional de la pérdida de la investidura. En Mora-Donatto, C. (Ed.), Relaciones entre Gobierno y Congreso: Memoria del VII Congreso Iberoamericano de Derecho Constitucional (pp.559-579). México D.F.: Universidad Nacional Autónoma de México.

Registraduría Nacional del Estado Civil (2015). Preguntas frecuentes. Recuperado de http://www.registraduria.gov.co/-Inscripcion-decandidatos,2667-.html-----

Vanegas, P. (2013).Las candidaturas en el derecho electoral colombiano. Bogotá: Universidad Externado de Colombia. 